\title{
Out-of-Pocket Costs and Oral Cancer Medication Discontinuation in the Elderly
}

\author{
Nantana Kaisaeng, PhD, MHA, MBA; Spencer E. Harpe, PharmD, PhD, MPH; and Norman V. Carroll, PhD
}

\section{ABSTRACT}

BACKGROUND: Cancer is a major cause of mortality and a major contributor to health care costs in the United States. An increasing number of cancer patients are treated with oral cancer therapy. Older patients are more likely to have cancer and to be at risk for adherence problems with oral cancer drugs. As a result of substantial cost sharing required for oral cancer drugs and the possibility of early entry into the Medicare Part D coverage gap, high out-of-pocket (0OP) drug costs could put elderly beneficiaries at great risk for delaying or discontinuing their cancer therapies.

OBJECTIVES: To (a) determine the 00P costs of oral cancer treatment and the numbers of patients that delay or discontinue oral cancer therapy and (b) examine the relationship between 00P costs and medication discontinuation or delay among older Medicare beneficiaries.

METHODS: A cross-sectional study was conducted using a 5\% sample of Medicare beneficiaries who filled a prescription for imatinib, erlotinib, anastrozole, letrozole, or thalidomide during 2008. Patients included in the analysis sample did not receive drug subsidies, were aged 65 years or older, and were enrolled in Medicare Part D for all 12 months of 2008. Logistic regression was used to determine the association between 00P costs and medication discontinuation or delay.

RESULTS: Mean 00P costs per day were $\$ 2.96$ for anastrozole, $\$ 3.10$ for letrozole, \$22.90 for imatinib, \$28.35 for erlotinib, and \$37.47 for thalidomide. The percentages of patients who discontinued or delayed oral cancer therapy were $58 \%$ for anastrozole, $64 \%$ for letrozole, $35 \%$ for imatinib, $61 \%$ for erlotinib, and $70 \%$ for thalidomide. For each $\$ 10$ increase in 00P spending per month, the likelihood of discontinuation or delay increased $13 \%$, $14 \%$, and $20 \%$ for imatinib, erlotinib, and thalidomide users, respectively, but decreased $26 \%$ for anastrozole and letrozole users.

CONCLUSION: Beneficiaries with higher 00P costs for the more expensive oral cancer drugs were more likely to discontinue or delay drug therapy.

J Manag Care Pharm. 2014;20(7):669-75

Copyright $\odot 2014$, Academy of Managed Care Pharmacy. All rights reserved.

\section{What is already known about this subject}

Cancer is a major cause of mortality and a major contributor to health care costs in the United States.

- An increasing number of cancer patients are treated with oral cancer therapy.

High cost is a major factor associated with nonadherence to medications.

\section{What this study adds}

Patients on the more expensive oral cancer drugs (imatinib, erlotinib, and thalidomide) had daily out-of-pocket (OOP) costs of around \$30; for patients on the less expensive drugs (anastrozole and letrozole), daily OOP costs averaged $\$ 3$.

Levels of medication discontinuation for the 5 drugs studied ranged from $35 \%$ of patients on imatinib to $70 \%$ of patients on thalidomide.

Higher OOP costs were associated with higher levels of medication discontinuation for patients on the more expensive drugs but not for those on the less expensive drugs.

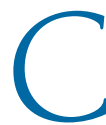

ancer is a major cause of mortality and a major contributor to health care costs in the United States. Recent statistics indicate that it is the second leading cause of death in the United States, ${ }^{1}$ that over 12 million patients suffer from the condition, ${ }^{2}$ and that annual direct costs for treatment were approximately $\$ 125$ billion. $^{3}$ An increasing number of cancer patients are treated with oral cancer therapy. In 2010, the oral cancer drug market was estimated to be between $\$ 5$ billion and $\$ 7$ billion with an annual growth rate between 20\% and $30 \%{ }^{4}$ More than $25 \%$ of the 400 antineoplastic drugs in the development pipeline are oral agents. ${ }^{5}$

Adherence is likely to be a major problem for patients on oral cancer drugs because of the high cost of these products. Most oral cancer drugs are branded and expensive medications that do not have generics available. High cost has been found to be a major factor associated with nonadherence to medications. ${ }^{6-9}$ Increased availability of oral chemotherapy and patients' inability to pay the high costs of oral cancer medications could result in increasing numbers of cancer patients stopping or delaying needed drug therapy.

In 2010, half of cancer survivors were older adults (aged 60 years or older). ${ }^{10}$ Older patients are more likely to have cancer and to be at risk for adherence problems with oral cancer drugs. ${ }^{11-13}$ The Medicare Part D program was implemented in 2006 to make prescription drugs more affordable for Medicare recipients, most of whom are older. However, the Part D program uses a number of strategies to decrease overall prescription drug costs. These strategies include cost sharing, which can be substantial for specialty products such as oral cancer drugs, and a coverage gap in which patients were, 
during the time of this study, responsible for $100 \%$ of their drug costs. The Patient Protection and Affordable Care Act (PPACA), which became effective in 2010, includes provisions that will eliminate the gap over a 10-year period. However, for the next several years, patients will continue to be responsible for a large portion of drug costs incurred in the coverage gap. ${ }^{14-15}$ Because of the high cost of oral cancer drugs, Medicare beneficiaries taking these therapies could enter the coverage gap early in the plan year. ${ }^{15}$ As a result of substantial cost sharing and early entry into the coverage gap, high out-of-pocket (OOP) drug costs could put these beneficiaries at great risk for delaying or discontinuing their cancer therapies. ${ }^{16-23}$

In this study, we determined the OOP costs of oral cancer treatment, and we examined the relationship between OOP costs and medication discontinuation or delay in older Medicare Part D beneficiaries. We hypothesized that high OOP cost of oral cancer drug treatment would increase the likelihood of medication discontinuation or delay. This study was approved by the Virginia Commonwealth University (VCU) Massey Cancer Center Protocol Review and Monitoring Committee Cancer Prevention and Control Subcommittee and the VCU Institutional Review Board for exemption according to 45 CFR 46.101 (b) Category 4.

\section{Methods}

We conducted a cross-sectional study using a 5\% random sample of 2008 Medicare Part D data compiled by the Centers for Medicare and Medicaid Services. The Beneficiary Summary File with Part D denominator data, Beneficiary Annual Summary File, Part D Event File with drug characteristics, and Plan Characteristics file were used. ${ }^{24}$ We obtained income information from the 2000 ZIP Code Tabulation Area (ZCTA)-level geography file (version 4). ${ }^{25}$ The 1999 median household income for householders aged 65-74 years and aged 75 years or older were linked with the Medicare dataset using the 5-digit ZIP code of residence. Incomes were adjusted to 2008 U.S. dollar values using the Consumer Price Index. ${ }^{26}$ The medications selected for our study included the 5 top selling oral cancer drugs by sales covered by Part D in 2008: anastrozole (Arimidex, AstraZeneca Pharmaceuticals, Wilmington, DE), imatinib (Gleevec, Novartis, East Hanover, NJ), erlotinib (Tarceva, OSI Pharmaceuticals, Farmingdale, NY), letrozole (Femara, Novartis, East Hanover, NJ), and thalidomide (Thalomid, Celgene, Summit, NJ). ${ }^{27}$

\section{Sample Selection}

The study sample included beneficiaries who (a) were aged 65 years or older at the beginning of 2008; (b) were continuously enrolled in the Medicare Part D program from January 1, 2008, through December 31, 2008; (c) filled a prescription for at least 1 of the 5 selected oral cancer medications between January 1 , 2008, and June 30, 2008; (d) were alive as of December 31,
2008; and (e) did not receive Part D prescription subsidies. We excluded beneficiaries whose first fill of an oral cancer drug occurred after June 30, 2008. This provided at least 6 months to identify patients' delay or discontinuation of medication. In addition, we restricted our sample to females among beneficiaries who used anastrozole or letrozole to treat breast cancer. National Comprehensive Cancer Network guidelines recommend using anastrozole or letrozole as adjuvant endocrine therapy for 5 years. ${ }^{28}$ As a result, we included only beneficiaries who were diagnosed with breast cancer since January 1, 2004, to ensure that discontinuation was not a result of completion of treatment. Part D data include a date of diagnosis for 5 selected cancers, one of which is breast cancer. Beneficiaries who switched between letrozole and anastrozole were excluded.

Of the other 3 drugs we examined, 2 are typically prescribed as maintenance therapy, and 1 may be prescribed as maintenance therapy. Imatinib is used in the chronic treatment of chronic myologenous leukemia. Erlotinib is used for secondline monotherapy or maintenance treatment for advanced or metastatic non-small cell lung cancer. Therapy with both imitanib and erlotinib is continued until the disease progresses or there is unacceptable toxicity. ${ }^{29,30}$ Thalidomide in combination with dexamethasone is used as maintenance treatment for multiple myeloma. However, thalidomide is also used in combination with bortezomib and dexamethasone as primary therapy for patients who anticipate stem cell transplant and with melphalan and prednisolone in patients not eligible for stem cell transplant. ${ }^{31}$ So, thalidomide is sometimes used as long-term maintenance therapy but also has significant use in shorter-term therapy.

\section{Descriptive Analyses}

Age, gender, and race were identified for beneficiaries taking each drug. We calculated mean OOP costs per day, per month, and per year for each drug. OOP costs per day were calculated as the sum of the total amount patients paid for the year divided by the total days' supply that he or she received. For patients with no gap in therapy and those who discontinued therapy, this consisted of all OOP costs for the drug over the study period divided by the total quantity of drug received over the study period. For patients who had a 30-day or greater gap in therapy, but then resumed therapy, OOP cost per day was based only on costs and quantity received before the gap in therapy. We calculated monthly OOP costs by multiplying OOP costs per day by 30 and annual OOP costs by multiplying OOP costs per day by 365 .

The percentage of beneficiaries who entered the Medicare Part D coverage gap and the time at which they entered the gap were identified. We also determined the length of time in months between the date the patient entered the coverage gap and the date that his or her initial prescription was filled. 
TABLE 1 Characteristics of Beneficiaries by Type of Oral Cancer Medication Used

\begin{tabular}{|c|c|c|c|c|c|c|c|c|c|c|}
\hline \multirow{2}{*}{$\begin{array}{l}\text { Characteristics } \\
\text { Age } \\
\end{array}$} & \multicolumn{2}{|c|}{$\begin{array}{c}\text { Imatinib } \\
(\mathrm{N}=123) \\
\text { Mean [SD] }\end{array}$} & \multicolumn{2}{|c|}{$\begin{array}{l}\text { Erlotinib } \\
(\mathrm{N}=96) \\
\text { Mean [SD] }\end{array}$} & \multicolumn{2}{|c|}{$\begin{array}{c}\text { Thalidomide } \\
(\mathrm{N}=87) \\
\text { Mean [SD] }\end{array}$} & \multicolumn{2}{|c|}{$\begin{array}{c}\text { Anastrozole } \\
(\mathrm{N}=2,397) \\
\text { Mean }[\mathrm{SD}]\end{array}$} & \multicolumn{2}{|c|}{$\begin{array}{l}\text { Letrozole } \\
(\mathrm{N}=1,078) \\
\text { Mean }[\mathrm{SD}]\end{array}$} \\
\hline & 75.3 & [6.39] & 76.61 & {$[6.55]$} & 74.65 & {$[6.34]$} & 75.33 & [7.08] & 74.76 & {$[7.07]$} \\
\hline Male (\%) & 53 & [43.09] & 23 & [23.96] & 40 & {$[45.98]$} & 0 & {$[0.0]^{\mathrm{a}}$} & 0 & {$[0.0]^{\mathrm{a}}$} \\
\hline Caucasian (\%) & 110 & {$[89.43]$} & 91 & {$[94.79]$} & 73 & {$[83.91]$} & 2,243 & {$[93.58]$} & 1,016 & [94.25] \\
\hline Number of comorbidities ${ }^{b}$ & 1.93 & [1.93] & 3.13 & {$[2.53]$} & 1.97 & {$[1.82]$} & 2.04 & [1.93] & 1.99 & [1.97] \\
\hline Number of noncancer drugs & 9.75 & [6.63] & 13.24 & [6.00] & 12.52 & [5.46] & 7.71 & {$[4.87]$} & 8.03 & [4.99] \\
\hline Beneficiaries with enhanced alternative benefit & & [51.61] & 50 & [52.08] & 54 & [62.07] & 1,384 & {$[57.74]$} & 614 & [56.96] \\
\hline Cost of noncancer drugs, ${ }^{\mathrm{c}} \$$ & $4,209.88$ & $2,160.78]$ & $3,633.70$ & $2,146.46]$ & $4,031.60$ & {$[2,313.76]$} & $1,091.92$ & {$[1,175.58]$} & $1,024.83$ & {$[1,175.11]$} \\
\hline \multicolumn{11}{|c|}{$\begin{array}{l}\text { a Only females were included in the analyses for anastrozole and letrozole. } \\
{ }^{b} \text { Number of comorbidities of those listed in Chronic Conditions Warehouse. }{ }^{32} \\
\text { cTotal out-of-pocket costs of noncancer drugs until beneficiaries delayed or discontinued. } \\
O O P=\text { out of pocket; } S D=\text { standard deviation. }\end{array}$} \\
\hline
\end{tabular}

We identified whether or not patients discontinued or delayed their oral cancer therapies. Medication delay was defined as at least a 30-day gap between the date that the patient's supply of the medication should have expired and the date that the patient obtained the next refill. Discontinuation was defined as the patient being without medication for at least 30 days and not having another refill during the study period.

\section{Statistical Analysis}

We initially conducted separate multinomial logistic regression analyses to examine the relationship between OOP costs and discontinuation and between OOP costs and delay for each drug. Because of insufficient sample size, a quasi-complete separation occurred when we conducted multinomial regression analyses. The results showed extremely large coefficients and standard errors for imatinib, thalidomide, and erlotinib. The results also indicated that the odds of discontinuation and the odds of delay were very similar. As a result, we combined the results for beneficiaries who delayed and those who discontinued in order to increase the sample size for the analyses.

The regression models included covariates that could influence the relationship between medication discontinuation and OOP costs. ${ }^{22}$ Covariates in the model included age, gender, race, total number of nonoral cancer drugs that patients were taking during the study period, total number of chronic conditions from which patients suffered as identified from variables provided in the Chronic Conditions Warehouse dataset ${ }^{32}$ and drug benefit type. The latter variable indicated the Part D benefit structure and contained 4 levels as follows: (1) defined standard benefit, (2) actuarially equivalent standard, (3) basic alternative, and (4) enhanced alternative. The defined standard benefit in 2008 offered the following:

- a deductible of $\$ 275$.

- $25 \%$ coinsurance in the period between the deductible and the coverage gap. The beneficiary entered the cover- age gap after incurring $\$ 2,510$ in total drug costs. This sum included the $\$ 833.75$ paid by the patient and the $\$ 1,676.25$ paid by the health plan.

- $100 \%$ coinsurance during the coverage gap.

- $5 \%$ coinsurance once the beneficiary emerged from the coverage gap into the catastrophic coverage phase. Beneficiaries left the coverage gap after incurring $\$ 5,726.25$ in total drug spending. At this point, the beneficiary would have spent $\$ 4,050.00$ and the health plan $\$ 1,676.25$.

The actuarially equivalent standard benefit offered the same deductible and coverage gap but different cost-sharing designs, such as tiered copays. The basic alternative structure offered reduced deductibles and/or changes in the level at which patients entered the coverage gap in addition to different cost-sharing designs. The enhanced alternative benefit offered lower cost sharing and coverage for some medications during the coverage gap. ${ }^{14}$ All statistical analyses were performed with SAS software version 9.3 (SAS Institute, Cary, NC) with an alpha level of $5 \%$.

\section{Results}

Of a total sample of 3,781 beneficiaries, the mean [SD] ages, depending on the specific oral cancer drug examined, were between 74.65 [6.34] and 76.61 [6.55] years. For imatinib, erlotinib, and thalidomide users, 54\%-76\% were female. Between $84 \%$ and $95 \%$ of beneficiaries were Caucasian (Table 1).

Mean [SD] OOP costs per day were $\$ 22.90$ [17.26] for imatinib, \$28.35 [16.82] for erlotinib, \$37.47 [29.15] for thalidomide, \$2.96 [1.83] for anastrozole, and \$3.10 [2.01] for letrozole. Annualized OOP costs were $\$ 8,358.50$ for imatinib, $\$ 10,347.75$ for erlotinib, $\$ 13,676.55$ for thalidomide, $\$ 1,080.40$ for anastrozole, and $\$ 1,131.50$ for letrozole (Table 2).

All imatinib and erlotinib users and about $99 \%$ of thalidomide users entered the coverage gap. In contrast, only $64 \%$ of 


\begin{tabular}{l|c|c|c|c|c}
\hline \multicolumn{7}{c}{ TABLE 2 } & \multicolumn{5}{c}{$\begin{array}{l}\text { Out-of-Pocket Costs of Oral } \\
\text { Cancer Medications }\end{array}$} \\
\hline Cost & Imatinib & Erlotinib & Thalidomide & Anastrozole & Letrozole \\
\hline Mean & 22.90 & 28.35 & 37.47 & 2.96 & 3.10 \\
\hline [SD] & {$[17.26]$} & {$[16.82]$} & {$[29.15]$} & {$[1.83]$} & {$[2.01]$} \\
\hline Median & 16.58 & 20.51 & 25.79 & 2.82 & 2.77 \\
\hline Range & $(10.30$, & $(4.31$, & $(8.08$, & $(0.31$, & 0.17 \\
& $129.57)$ & $84.29)$ & $147.78)$ & $9.16)$ & $9.30)$ \\
\hline Annual & $8,358.50$ & $10,347.75$ & $13,676.55$ & $1,080.40$ & $1,131.50$ \\
OOP cost (\$) & & & & & \\
\hline aAnnual OOP costs were calculated as daily costs multiplied by 365. \\
OOP=out of pocket. \\
\hline
\end{tabular}

beneficiaries on letrozole and $71 \%$ of those on anastrozole entered the coverage gap. A large majority of beneficiaries who used imatinib (88\%), erlotinib (99\%), and thalidomide (98\%) entered the coverage gap at the time of their first prescription fill. In contrast, only $1 \%$ of beneficiaries who filled anastrozole or letrozole entered the coverage gap at the time of their first fill. About half of these beneficiaries had not reached the gap 5 months after the time of their first fill. While the great majority of beneficiaries who used imatinib (97\%), erlotinib (99\%), and thalidomide (87\%) entered the catastrophic coverage phase, only $10 \%$ of anastrozole users and $9 \%$ of letrozole users entered this phase. The total number of beneficiaries who delayed or discontinued their treatment was 43 (34.96\%) for imatinib, 59 (61.46\%) for erlotinib, 61 (70.11\%) for thalidomide, 1,402 (58.49\%) for anastrozole, and 694 (64.38\%) for letrozole.

In the unadjusted models, the odds ratios for the relationship between OOP costs and medication discontinuation or delay were $1.011(P<0.0001 ; 95 \%$ confidence interval $[\mathrm{CI}]=1.006$ 1.017) for imatinib; $1.011(P<0.0001 ; 95 \% \mathrm{CI}=1.005-1.016)$ for erlotinib; $1.011(P=0.0002 ; 95 \% \mathrm{CI}=1.005-1.016)$ for thalidomide; $0.973(P<0.0001,95 \% C I=0.971-0.975)$ for anastrozole; and $0.974(P<0.0001,95 \% \mathrm{CI}=0.971-0.977)$ for letrozole.

In the adjusted models, the odds ratios for the relationship between OOP costs and medication discontinuation or delay were $1.012(P=0.0001)$ for imatinib, $1.013(P=0.0001)$ for erlotinib, and $1.018(P=0.0021)$ for thalidomide. This indicated that, as hypothesized, the odds of discontinuation or delay increased as OOP costs increased. However, we found unexpected results among anastrozole and letrozole users. The odds of discontinuation or delay decreased significantly as OOP costs increased in these patients. The odds of medication discontinuation or delay were $0.970(P=0.0001)$ for anastrozole and $0.971(P=0.0001)$ for letrozole.

The previous results are based on a $\$ 1$ increase in monthly OOP costs, but a more realistic increase may be beneficial for interpretation. For each $\$ 10$ increase in OOP cost per month, the odds of discontinuation or delay increased $12.7 \%$ for imatinib users, $13.8 \%$ for erlotinib users, and $19.5 \%$ for thalidomide users. However, the odds of discontinuation or delay decreased
26.3\% for anastrozole users and 25.5\% for letrozole users. These estimates were made by multiplying the regression coefficient for OOP costs by 10 then exponentiating the product.

\section{Discussion}

Our findings indicate that Medicare Part D beneficiaries on oral cancer drugs experience high OOP costs for these drugs, that substantial numbers of them delay or discontinue treatment, and that there is a significant association between OOP costs and delay or discontinuation. The results also indicated 2 distinct patterns of costs and behavior.

For the more expensive drugs-imitanib, erlotinib, and thalidomide-average OOP costs per day ranged from $\$ 22.90$ to $\$ 37.47$. This was a result of the high cost of these products and the structure of cost sharing in the Part D program. Medicare permits high cost medications to be placed on "specialty tiers" that frequently use coinsurance (in which patients' cost share is calculated as a percentage of the drug's cost) rather than the fixed dollar copayments that are more common for nonspecialty drugs. An overwhelming majority of patients in our sample were subject to a $25 \%$ or larger coinsurance for their oral cancer drugs. Further, a large majority of patients on the more expensive therapies entered the coverage gap on their first fill of their oral cancer drug and exited the gap on their second fill. As a result, these patients experienced extremely high OOP costs for the first few months of treatment. Then, after they reached the catastrophic phase, they had much lower costs for the rest of the year. The results of the logistic regression suggest that high OOP costs are an important reason that so many beneficiaries-between 35\% and 70\% in our sample-discontinued or delayed the more expensive cancer therapies. Delays and discontinuation could result in progression or increased severity of disease, leading to hospitalization, mortality, and increasing health care expenditures. ${ }^{33-36}$ This result suggests that more comprehensive coverage for these drugs may result in higher compliance and better outcomes of therapy.

There was a much different pattern of costs and behavior for patients on the less expensive oral cancer drugs-anastrozole and letrozole. These patients had much lower OOP costs that averaged around $\$ 3$ per day. Further, most of these patients did not enter the coverage gap until after their fifth month taking the drug. As a result, for a significant part of the year, most patients on the less expensive oral cancer drugs had relatively low OOP costs. The results of the logistic regression indicated a negative association between OOP costs and drug discontinuation or delay for these patients; increased costs were associated with decreased odds of discontinuation or delay. This was contrary to our hypothesis. This counter-intuitive finding may be a result of the pattern of OOP payments for these patients. Patients that discontinued before, or shortly after, reaching the coverage gap would have had relatively low OOP costs for the entire period they were taking their drugs. Patients that 
continued therapy after reaching the coverage gap would have had much higher costs as a result of having to pay the full cost of their drugs while in the coverage gap. This would result in a situation in which patients who discontinued therapy would have had lower OOP costs than those who continued therapy.

Medicare Part D was intended to make prescription drugs affordable for elderly beneficiaries. Our results suggest that, despite the coverage provided by Part $\mathrm{D}$, beneficiaries on expensive drugs, including 3 of the oral cancer drugs in this study, experience high OOP costs. The Affordable Care Act provided expanded coverage for Medicare Part D beneficiaries such that the coverage gap will be fully closed by 2020 . However, even after the gap is closed, Part D beneficiaries will be required to pay $25 \%$ for covered prescriptions after meeting the deductible and before reaching the catastrophic phase. ${ }^{37}$ This provision indicates that OOP costs will continue to be high, especially for beneficiaries using brand name medications without generic equivalents, because of the high cost of these products and the substantial coinsurance rates. Further efforts, such as caps on monthly copays or maximum annual OOP limits, may be needed to ensure that the more expensive oral cancer therapies are affordable for Part D beneficiaries.

\section{Limitations}

Our study was subject to a number of limitations. First, our data did not distinguish between beneficiaries who delayed or discontinued therapy due to high cost from those who discontinued for other reasons. Clinical trial results have documented discontinuation rates due to intolerance of $8 \%-15 \%$ for thalidomide users, ${ }^{38-42}$ 5\%-11\% for erlotinib users, ${ }^{43-44}$ and 26\%-29\% for imatinib users. ${ }^{45-47}$ These rates are substantially below the rates of $70 \%, 61 \%$, and $35 \%$, respectively, found in our study. The discontinuation rates in patients taking anastrozole or letrozole in clinical trials ranged between $19 \%$ and $29 \% .^{11,48,49}$ Again, these are well below the rates of $58 \%$ and $64 \%$ found in our study. While some of the higher discontinuation rates in our study may have been a result of our data coming from real-world (as compared with clinical trial) settings, the higher rates also provide additional evidence of a cost-related effect on discontinuation and delay.

Four of the drugs in our study-anastrozole, letrozole, imatinib, and erlotinib-are typically used as chronic, long-term therapies. The fifth drug-thalidomide-is sometimes used as a maintenance therapy and sometimes used as short-term therapy. As a result, some of the discontinuation noted for thalidomide could have been because patients finished their prescribed course of therapy, not as a result of high OOP costs.

Moreover, our data did not provide cancer stage information; we did not know if patients were in the later or at the beginning stages of cancer. Late-stage or severely ill patients might be more likely to stop their therapy and switch to palliative care. Also, late-stage patients with high OOP payments might believe the treatment has less benefit to them and discontinue the treatment.
We did not have information about cancer drugs that were covered by Medicare Part B. Consequently, we were unable to determine the extent to which patients switched from oral medications to injections or the extent to which patients who received cancer drugs under both Part B and Part D continued their Part B medication without taking their Part D medication. However, practice guidelines for treatment of the cancers in our study recommend prescribing intravenous drugs as firstline therapy. ${ }^{28,30,31}$ Part D-covered oral cancer drugs are used primarily as alternative or adjuvant treatment. ${ }^{28,30,31}$ As a result, the amount of switching between oral and parenteral therapy was not likely to be large.

This study employed a cross-sectional design in which only 2008 Part D data were used. The impact of OOP costs should be investigated in the long term. Because we used only 1 year's data, it was not possible to determine whether beneficiaries that delayed or discontinued their therapy late in the year had completely discontinued or whether they resumed therapy in the following year. Also, a long-term study would allow us to examine the outcomes of discontinuation and delay.

Finally, previous studies have indicated that income influences patient adherence to their medications. The income variable used in our study, which was median household income data for the ZIP code of residence, was not associated with medication discontinuation. This may have been because the income measure we used was not sufficiently precise.

\section{Conclusion}

We examined the costs and discontinuation or delay of oral cancer drug therapy in the Medicare Part D population. We found that these beneficiaries experienced high OOP costs for their therapies, that approximately 35\%-70\% delayed or discontinued their therapies during a 1-year period, and that beneficiaries with higher OOP costs for the more expensive cancer therapies were more likely to delay or discontinue that therapy.

\section{Authors}

NANTANA KAISAENG, PhD, MHA, MBA, is Pharmacist, Thai Food and Drug Administration, Nonthaburi, Thailand; NORMAN V. CARROLL, PhD, is Professor of Pharmacoeconomics and Health Outcomes, Virginia Commonwealth University, Richmond, Virginia; and SPENCER E. HARPE, PharmD, PhD, MPH, is Associate Professor of Pharmacy Administration, Midwestern University Chicago College of Pharmacy, Downers Grove, Illinois.

AUTHOR CORRESPONDENCE: Norman V. Carroll, PhD, Virginia Commonwealth University, 410 N. 12th St., P.O. Box 980533 , Richmond, VA 23298. Tel.: 804.828.2587; Fax: 804.628.3991;

E-mail:nvcarroll@vcu.edu. 


\section{DISCLOSURES}

The authors report no potential conflicts of interest.

Carroll was primarily responsible for study concept and design, assisted by Kaisaeng and Harpe. Carroll and Kaisaeng collected the data, which were interpreted by Harpe, Carroll, and Kaisaeng. The manuscript was written primarily by Kaisaeng, assisted by Carroll and Harpe, and revised by Kaisaeng, Carroll, and Harpe.

\section{REFERENCES}

1. Hoyert DL, Xu J. Deaths: preliminary data for 2011. Natl Vital Stat Rep. 2012;61(6):1-50. Available at: http://www.cdc.gov/nchs/data/nvsr/nvsr6l/ nvsr61_06.pdf. Accessed May 82014.

2. Howlader N, Noone AM, Krapcho M, et al. SEER cancer statistics review, 1975-2009. National Cancer Institute. April 2012. Bethesda, MD, based on November 2011 SEER data submission. Available at: http://seer.cancer.gov/ csr/1975_2009_pops09/browse_csr.php?section=2\&page=sect_02_table.21. html. Accessed May 12, 2014

3. National Cancer Institute. The cost of cancer. 2011. Available at: http:// www.cancer.gov/aboutnci/servingpeople/understanding-burden/costofcancer. Accessed May 23, 2014

4. Reese DW, Skyberg JT, Kuntz GA. Oral oncology treatment regimens and the role of medication therapy management on patient adherence and compliance. 2009. Available at: http://accc-cancer.org/publications/pdf/usoncologywhitepaper.pdf. Accessed May 12, 2014.

5. Weingart SN, Brown E, Bach PB, et al. NCCN Task Force Report: oral chemotherapy. J Natl Compr Canc Netw. 2008;6(Suppl 3):S1-S14.

6. Kennedy J, Tuleu I, Mackay K. Unfilled prescriptions of Medicare beneficiaries: prevalence, reasons, and types of medicines prescribed. J Manag Care Pharm. 2008;14(6):553-60. Available at: http://www.amcp.org/WorkArea/ DownloadAsset.aspx?id=7948

7. Ellis JJ, Erickson SR, Stevenson JG, Bernstein SJ, Stiles RA, Fendrick AM Suboptimal statin adherence and discontinuation in primary and secondary prevention populations. J Gen Intern Med. 2004;19(6):638-45.

8. Castaldi PJ, Rogers WH, Safran DG, Wilson IB. Inhaler costs and medication nonadherence among seniors with chronic pulmonary disease. Chest. 2010;138(3):614-20.

9. Conwell LJ, Esposito D, Colby M, et al. Promising therapies, prohibitive costs: a qualitative assessment of the effects of the Medicare Part D doughnut hole on access to costly cancer medications. Community Oncol. 2011;8(3):111-17.

10. American Cancer Society. Cancer treatment and survivorship: facts \& figures 2012-2013. Atlanta, GA: American Cancer Society; 2012. Available at: http://www.cancer.org/acs/groups/content/@epidemiologysurveilance/ documents/document/acspc-033876.pdf. Accessed May 12, 2014.

11. Hershman DL, Kushi LH, Shao T, et al. Early discontinuation and nonadherence to adjuvant hormonal therapy in a cohort of 8,769 early-stage breast cancer patients. J Clin Oncol. 2010;28(27):4120-28.

12. Partridge AH, Wang PS, Winer EP, Avorn J. Nonadherence to adjuvant tamoxifen therapy in women with primary breast cancer. J Clin Oncol. 2003;21(4):602-06

13. Owusu C, Buist DS, Field TS, et al. Predictors of tamoxifen discontinuation among older women with estrogen receptor-positive breast cancer. J Clin Oncol. 2008;26(4):549-55.

14. O'Sullivan J. Medicare Part D prescription drug benefit: a primer. Congressional Research Service Report for Congress. 2008. Available at: http://amcp.org/WorkArea/DownloadAsset.aspx?id=11060.

15. Barnes L, Burich M, Little A, Nowak M, Haroldson B. Oral oncolytics: addressing the barriers to access and identifying areas for engagement. February 2010. Available at: http://www.communityoncology.org/pdfs/avalerecoa-oral-oncolytics-study-summary-report.pdf. Accessed May 12, 2014.
16. Nekhlyudov L, Madden J, Graves AJ, et al. Cost-related medication nonadherence and cost-saving strategies used by elderly Medicare cancer survivors. J Cancer Surviv. 2011;5(4):395-404.

17. Castaldi PJ, Rogers WH, Safran DG, Wilson IB. Inhaler costs and medication nonadherence among seniors with chronic pulmonary disease. Chest. 2010;138(3):614-20

18. Melloni C, Alexander KP, Ou FS, et al. Predictors of early discontinuation of evidence-based medicine after acute coronary syndrome. Am J Cardiol. 2009;104(2):175-81.

19. Curkendall S, Patel V, Gleeson M, Campbell RS, Zagari M, Dubois R. Compliance with biologic therapies for rheumatoid arthritis: do patient outof-pocket payments matter? Arthritis Rheum. 2008;59(10):1519-26.

20. Garavalia L, Garavalia B, Spertus JA, Decker C. Exploring patients' reasons for discontinuance of heart medications. J Cardiovasc Nurs. 2009;24(5):371-79.

21. Daugherty KK, Butler JS, Mattingly M, Ryan M. Factors leading patients to discontinue multiple sclerosis therapies. J Am Pharm Assoc (2003). 2005:45(3):371-75

22. Piette JD, Heisler M, Horne R, Alexander, GC. A conceptually based approach to understanding chronically ill patients' responses to medication cost pressures. Soc Sci Med. 2006;62(4):846-57.

23. Zivin K, Ratliff S, Heisler MM, Langa KM, Piette JD. Factors influencing cost-related nonadherence to medication in older adults: a conceptually based approach. Value Health. 2010;13(4):338-45.

24. Research Data Assistance Center (RESDAC). Medicare data documentation. Available at: http://www.resdac.org/ddvh/index.asp. Accessed May 12, 2014.

25. Research Triangle Institute (RTI). RTI spatial impact factor datadownload-data. Available at: https://rtispatialdata.rti.org/Download/Data/ tabid/56/Default.aspx. Accessed May 12, 2014.

26. Bureau of Labor Statistics. Consumer Price Index research series using current methods (CPI-U-RS). Available at: http://www.bls.gov/cpi/cpiursai1978_2010.pdf. Accessed May 12, 2014.

27. Lamb E. Top 200 drugs of 2008. Pharmacy Times. May 15, 2009. Available at: http://www.pharmacytimes.com/publications/issue/2009/200905/RxFocusTop200Drugs-0509. Accessed May 12, 2014

28. National Comprehensive Cancer Network. Clinical practice guidelines in oncology: breast cancer. Version 2. 2011. Available at: http://www.nccn.org/ professionals/physician_gls/f_guidelines.asp\#site. Accessed May 12, 2014.

29. National Comprehensive Cancer Network. Clinical practice guidelines in oncology: chronic myelogeneous leukemia. Version 2. 2012. Available at: http://www.nccn.org/professionals/physician_gls/f_guidelines.asp\#site. Accessed May 12, 2014.

30. National Comprehensive Cancer Network. Clinical practice guidelines in oncology: non-small cell lung cancer. Version 2. 2012. Available at: http:// www.nccn.org/professionals/physician_gls/f_guidelines.asp\#site. Accessed May 12, 2014

31. National Comprehensive Cancer Network. Clinical practice guidelines in oncology: multiple myeloma. Version 1. 2013. Available at: http://www. nccn.org/professionals/physician_gls/f_guidelines.asp\#site. Accessed May 12,2014 .

32. Chronic Conditions Data Warehouse. Chronic condition categories. Centers for Medicare \& Medicaid Services. Available at: http://www.ccwdata.org/chronic-conditions/index.htm. Accessed May 12, 2014.

33. Davis KL, Candrilli SD, Edin HM. Prevalence and cost of nonadherence with antiepileptic drugs in an adult managed care population. Epilepsia. 2008;49(3):446-54

34. Darkow T, Henk HJ, Thomas SK, et al. Treatment interruptions and non-adherence with imatinib and associated healthcare costs: a retrospective analysis among managed care patients with chronic myelogenous leukaemia. Pharmacoeconomics. 2007;25(6):481-96. 
35. Egede LE, Gebregziabher M, Dismuke CE, et al. Medication nonadherence in diabetes: longitudinal effects on costs and potential cost savings from improvement. Diabetes Care. 2012;35(12):2533-39.

36. Gilmer TP, Dolder CR, Lacro JP, et al. Adherence to treatment with antipsychotic medication and health care costs among Medicaid beneficiaries with schizophrenia. Am J Psychiatry. 2004;161(4):692-99.

37. Center for Medicare \& Medicaid Services. Information pharmacists can use on: closing the coverage gap. Revised May 2013. Available at: http://www.cms.gov/Outreach-and-Education/Outreach/Partnerships/ Downloads/11522-P.pdf. Accessed May 12, 2014.

38. Cavo M, Zamagni E, Tosi P, et al. First-line therapy with thalidomide and dexamethasone in preparation for autologous stem cell transplantation for multiple myeloma. Haematologica. 2004;89(7):826-31.

39. Prince HM, Schenkel B, Mileshkin L. An analysis of clinical trials assessing the efficacy and safety of single-agent thalidomide in patients with relapsed or refractory multiple myeloma. Leuk Lymphoma. 2007;48(1):46-55.

40. Offidani M, Leoni P, Bringhen S, et al. Melphalan, prednisone, and thalidomide versus thalidomide, dexamethasone, and pegylated liposomal doxorubicin regimen in very elderly patients with multiple myeloma: a casematch study. Leuk Lymphoma. 2010;51(8):1444-49.

41. Zamagni E, Petrucci A, Tosi P, et al. Long-term results of thalidomide and dexamethasone (thal-dex) as therapy of first relapse in multiple myeloma. Ann Hematol. 2012;91(3):419-26.

42. van Rhee F, Dhodapkar M, Shaughnessy JD Jr, et al. First thalidomide clinical trial in multiple myeloma: a decade. Blood. 2008;112(4):1035-38.
43. Kelly K, Azzoli CG, Zatloukal P, et al. Randomized phase 2b study of pralatrexate versus erlotinib in patients with stage IIIB/IV non-small-cell lung cancer (NSCLC) after failure of prior platinum-based therapy. J Thorac Oncol. 2012;7(6):1041-48

44. Johnson JR, Cohen M, Sridhara R, et al. Approval summary for erlotinib for treatment of patients with locally advanced or metastatic non-small cell lung cancer after failure of at least one prior chemotherapy regimen. Clin Cancer Res. 2005;11(18):6414-21.

45. Marin D, Bazeos A, Mahon FX, et al. Adherence is the critical factor for achieving molecular responses in patients with chronic myeloid leukemia who achieve complete cytogenetic responses on imatinib. J Clin Oncol. 2010;28(14):2381-88.

46. Ganesan P, Sagar TG, Dubashi B, et al. Nonadherence to imatinib adversely affects event free survival in chronic phase chronic myeloid leukemia. Am J Hematol. 2011;86(6):471-74.

47. Ibrahim AR, Eliasson L, Apperley JF, et al. Poor adherence is the main reason for loss of CCyR and imatinib failure for chronic myeloid leukemia patients on long-term therapy. Blood. 2011;117 (14):3733-36.

48. Partridge AH, LaFountain A, Mayer E, et al. Adherence to initial adjuvant anastrozole therapy among women with early-stage breast cancer. J Clin Oncol. 2008;26(4):556-62.

49. Danilak M, Chambers CR. Adherence to adjuvant endocrine therapy in women with breast cancer. J Oncol Pharm Pract. 2013;19(2):105-10. 